\title{
Response of Flash Flood Early Warning Critical Rainfall to Storm Pattern in South Branch of Censhui Watershed
}

\author{
Changzhi Li, Baozhao Yuan, Miao Zhang, Changjun Liu and Dongya Sun \\ Department of Water Hazards Reduction, China Institute of Water Resources and Hydropower Research, Beijing 100038, China
}

\begin{abstract}
Critical rainfall estimation for early warning of rainstorm-induced flash flood is an inverse rainstorm-runoff process based on warning discharge threshold for a warning station of interest in a watershed. The key aspects of critical rainfall include rainfall amount and rainfall duration. Storm pattern affects highly the estimation of critical rainfall. Using hydrological modeling technique with detailed sub-basin delineation and manual for design rainstorm-runoff computation, this study first introduced basic concept and analysis methods on critical rainfall for flash flood early warning, then, investigated the responses of flash flood warning critical rainfall to storm pattern. Taking south branch of Censhui watershed in China as an example, critical rainfall in case of typical storm patterns for early warning of rainstorm-induced flash flood were estimated at 3 warning stations. This research illustrates that storm pattern plays important role in the estimation of critical rainfall and enough attention should also be paid to storm pattern when making a decision on whether a warning to be issued or not.
\end{abstract}

Key words: Flash flood early warning, critical rainfall, storm pattern, response.

\section{Introduction}

Rainstorm-induced flash flood can be characterized as abrupt occurrence, short rainfall duration, high storm intensity and destructive damage. Flash flood disasters are rising and drawing substantial attention around the world and flash flood early warning becomes one of the key issues for lives and properties protection in mountainous or hilly areas. Flash flood early warning is often conducted using critical rainfall as a warning indicator. Critical rainfall is commonly defined as an estimate of rainfall amount required over a given watershed and duration to cause a mountain stream to flood and may result in disaster at a given warning station. Various methods for critical rainfall estimation have been widely used for the purpose of flash flood early warning. Generally speaking, these methods can be classified as two categories. The first one provides dynamical critical rainfall amounts for a large area in next $1 \mathrm{~h}, 3 \mathrm{~h}, 6 \mathrm{~h}, 12 \mathrm{~h}$ and $24 \mathrm{~h}$ with new input of predicated precipitation. The Flash Flood

Corresponding author: Changezhi Li, Ph.D., main research field: flood defense.
Guidance system (FFG) [1, 2], for instance, a famous one of this category and developed by the United States is commonly used in USA and many other countries and regions [3-6]. This method has been continuously improving and refining [2, 7]. The second one is to find out critical rainfall amount according to typical designing conditions (including design storm pattern, soil moisture content and fixed rainfall duration). Most methods used in current China belong to this category, such as statistical analysis of measured rainfall data, warning stage/warning discharge calculation, rainstorm critical curve method and hydrodynamic method [8-11], The method of Jan, C. D. [12, 13] focuses on rainfall intensity and accumulative rainfall amount. In recent years, more detailed data and refined methods have been used to explore flash flood early warning [14-17], especially for regions without runoff records [18]. Some researches paid attention to how storm pattern to affect critical rainfall evaluation [16]. China has mountainous and hilly area around $2 / 3$ of land that are flash-flood-prone area and most current critical rainfall depth was estimated based on fixed design conditions without change of storm pattern. 
Therefore, it is valuable to discuss how the critical rainfall responses to storm pattern. Taking the south branch of Censhui watershed in Huan province as an example, this study, aiming at rainstorm-induced flash flood, attempts to discuss this problem. And it is developed as follows: firstly, a description of the studied area is given; secondly, the approach and model on critical rainfall analysis is introduced; thirdly, it is presented the factors affecting critical rainfall analysis, including three typical storm patterns; finally, the response of critical rainfall to rain storm is evaluated and results are discussed.

\section{Description of Studied Area}

Located in Hunan province (11313'25.3"-11329'14.8" $\left.29^{\circ} 43^{\prime} 29.01^{\prime \prime}-29^{\circ} 51^{\prime} 27^{\prime \prime} \mathrm{N}\right)$ with an drainage area of $223 \mathrm{~km}^{2}$ and longest flow way of $33.6 \mathrm{~km}$, the south branch of Censhui watershed is a wet subtropical monsoon climate region with an annual precipitation of 1,200-1,900 mm. Rainfall concentrates and heavy storms often triggers flash flood in this area in summer. The watershed is bordered by mountains at west, south and north, and the elevations descent from west to east. The south branch of Censhui creek originates from Yanzi village, Shimen county. It flows in the valley eastwards through 5 towns and enters into Wangjiachang reservoir. The creek consists of 3 main tributaries. The tributary 1 is located at the most upstream. It flows mainly through Shimen county and Lixian county. The watershed is predominately wooded mountainous area covered with light to dense trees and grass. The flash flood early-warning stations are marked as A, B and C. Station A is located near the mouth of the main creek, the backwater area of Wanjiachang reservoir. The recipient of the warning is an enterprise. Station B is located at the confluence of the tributary 2 and the main creek, its recipient is a town crossing the main creek by a bridge. Station $\mathrm{C}$ is located at the confluence of the tributary 1 and the main creek, its recipient is a confluence. There was a hydrologic station-Lianhuayuan station, located between warning station B and warning station A on the main creek (Fig. 1), which was removed after the construction of Wangjiachang reservoir. Moreover, there was a rain gauge station, Liangshuijing station, in the upper reach of the main creek (Fig. 1).

In the past, this watershed has been frequently attacked by flash flood. Major flood damages occurred during the storm events of 1909, 1935, 1954, 1963, 1966, 1980, 1983, 1998 and 2003. The historical streamflow data of the Lianhuayan station indicates that during 1909's flash flood event, the recorded peak discharge and river stage reached $1,980 \mathrm{~m}^{3} / \mathrm{s}$ and $94.32 \mathrm{~m}$, respectively. During 1935's event, the peak discharge and river stage reached $1,290 \mathrm{~m}^{3} / \mathrm{s}$ and $93.35 \mathrm{~m}$, respectively. During 1966's event, the peak discharge and river stage reached $667 \mathrm{~m}^{3} / \mathrm{s}$ and $93.11 \mathrm{~m}$, respectively.

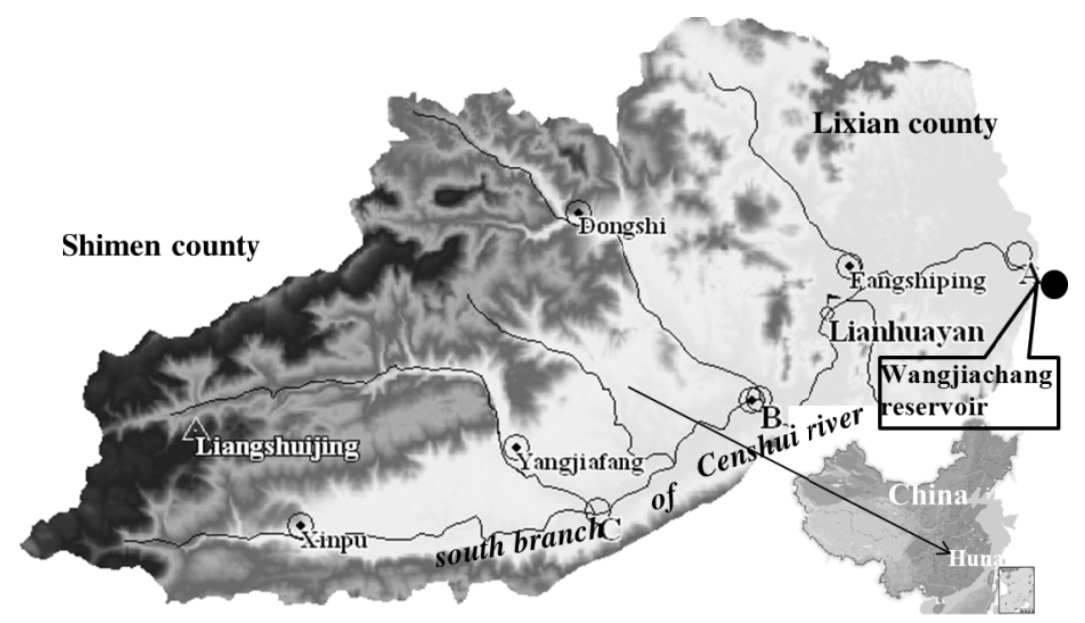

Fig. 1 Sketch of south branch of Censhui watershed. 


\section{Critical Rainfall Analysis}

\subsection{Basic Concept and Approach}

Critical rainfall for flash flood early warning is essentially an inverse hydrological problem of rainstorm-runoff process based on warning discharge threshed for a warning station of interest in a watershed. Rainfall amount and rainfall duration are the key aspects of critical rainfall. The basic concept and approach in this study are: using detailed hydrological modeling to simulate flood hydrographs at various early warning stations inside a watershed; determining the lag time based on the peak-precipitation time and peak-flood time and using the lag time to backtrack critical rainfall depth at each early warning station as shown in Fig. 2. During the development of the detailed hydrological model, special attention was paid to: (1) in the process of sub-basin delineation, the geographical locations of the early-warning stations was appropriately considered as well as the river sections, source and sink points, tributary confluences and diversions; (2) carefully collect and input parameters for each sub-basin such as topographical features, vegetation covers, land uses types, soil types and river features and (3) utilizing historical and typical precipitation and streamflow data in the watershed to calibrate and validate the model.

On the base of the development of the detailed hydrological model, the analysis was performed according to the steps: (1) determining rainfall duration according to analysis on time of concentration of a watershed; (2) estimating the warning discharge threshold for each warning station based on its warning stage using discharge and water stage transformation, for instance, Manning's formula; (3) assuming typical soil moisture conditions for runoff volume analysis; (4) selecting rainfall pattern for precipitation series input for hydrological analysis. A hypothetical precipitation series was constructed by assuming an initial total rainfall depth and distributing the total rainfall amount to each time step based on the rainfall pattern and (5) critical rainfall computation and analysis was conducted by error and trial procedure, this hypothetical precipitation series in step 4 was input into the model, and the resulted flood hydrograph at each early-warning station was compared with pre-determined warning discharge. If computed peak flow differs from warning discharge significantly, the initial total rainfall amount will be adjusted. And the simulation repeats until the simulated peak flow at each early warning station

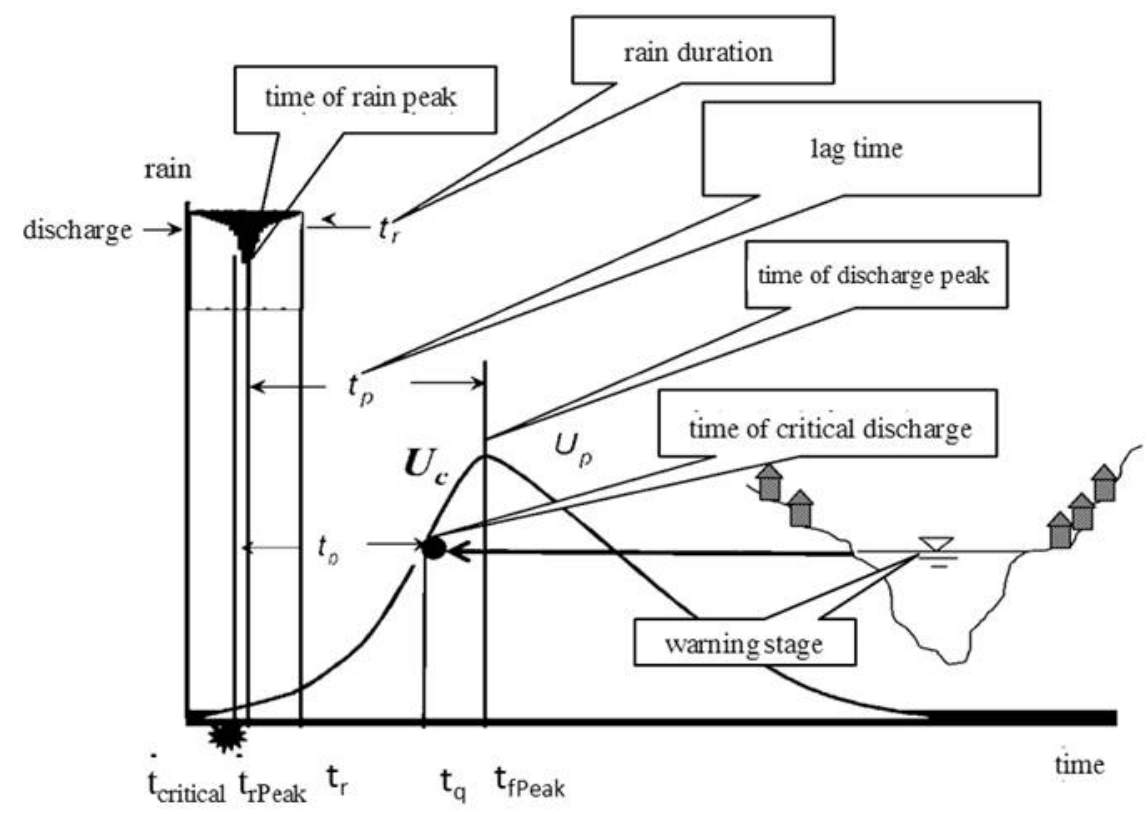

Fig. 2 Schematics for estimating critical rainfall. 
matches pre-determined warning discharge within pre-defined tolerance.

\subsection{Model Development and Calibration}

\subsubsection{Model Development}

HEC-HMS computer software developed by USACE was used to conduct this research for its flexibility and commonality for rainstorm-runoff process simulation. According to the river networks and its 3 specific spatial locations of the early-warning stations, the watershed is divided into 8 sub-basins, 4 river reaches, and 5 junction points in this study. The sketch of the model basics and early-warning stations are illustrated in Fig. 3.

The SCS curve number method was used to compute the loss before the start of surface runoff; the SCS unit hydrograph transform method was used to estimate surface runoff, and the exponential recession model was used to calculate watershed base flow. The major characteristics for each sub-basin are listed in Table 1.

The flood flow was routed through river reaches with the kinematic-wave method for the considerable slope of channel. Table 2 presents the detailed and key information for each river reach, including creek name, creek length, slope of channel, shape of cross section and side-slope.

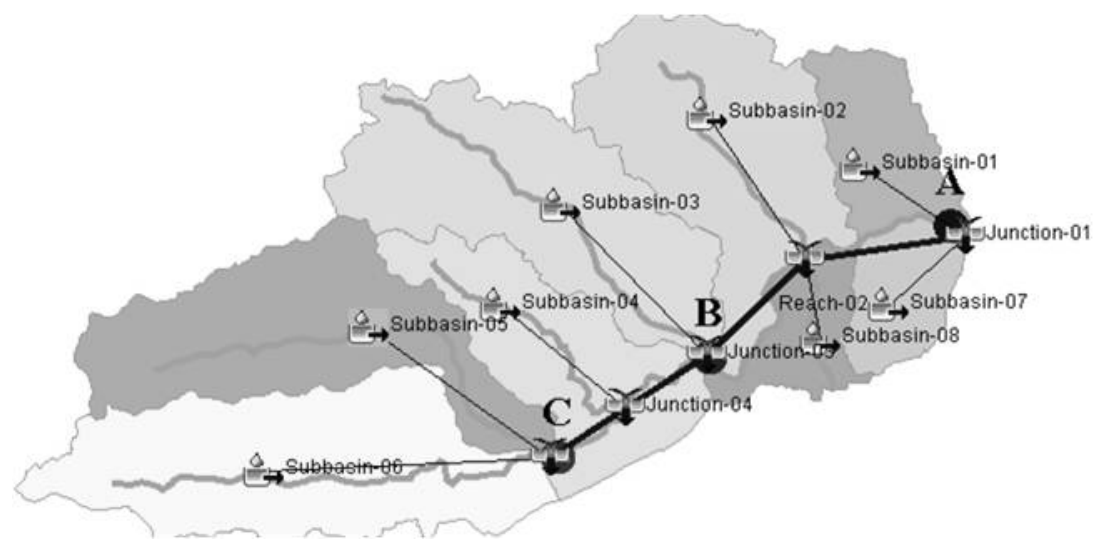

Fig. 3 Watershed delineation and early warning stations.

Table 1 Major characteristic for Censhui watershed sub-basins.

\begin{tabular}{|c|c|c|c|c|c|c|c|c|c|}
\hline No & Subbasin & $\begin{array}{l}\text { Area } \\
\left(\mathrm{km}^{2}\right)\end{array}$ & $\begin{array}{l}\text { Initial } \\
\mathrm{CN}\end{array}$ & $\begin{array}{l}\text { Calibrated } \\
\mathrm{CN}\end{array}$ & $\begin{array}{l}\text { Impervious } \\
\text { area (\%) }\end{array}$ & Land cover & $\begin{array}{l}\text { Total } \\
\text { volume }\end{array}$ & $\begin{array}{l}\text { Direct } \\
\text { runoff }\end{array}$ & Base flow \\
\hline 1 & Sub-1 & 13.90 & 75 & 1 & 9 & Wood/Grassland & \multirow{8}{*}{ SCS CN } & \multirow{8}{*}{ SCS UH } & \multirow{8}{*}{ Recession } \\
\hline 2 & Sub-2 & 38.37 & 75 & / & 8 & Wood/Grassland & & & \\
\hline 3 & Sub-3 & 40.84 & 75 & 71 & 10 & Wood/Grassland & & & \\
\hline 4 & Sub-4 & 27.80 & 82 & 77 & 8 & Wood/Grassland & & & \\
\hline 5 & Sub-5 & 38.38 & 75 & 71 & 8 & Wood/Grassland & & & \\
\hline 6 & Sub-6 & 44.75 & 75 & 71 & 6 & Wood/Grassland & & & \\
\hline 7 & Sub-7 & 9.74 & 75 & 1 & 6 & Wood/Grassland & & & \\
\hline 8 & Sub-8 & 9.59 & 75 & l & 5 & Wood/Grassland & & & \\
\hline
\end{tabular}

* The sign " ") in the column "Calibrated CN" means the non-calibrated CN value in the downstream of Lianhuayan station.

Table 2 Major characteristics for each river reach.

\begin{tabular}{|c|c|c|c|c|c|c|c|}
\hline No. & River reach & Length (m) & $\begin{array}{l}\text { Channel } \\
\text { slope (\%o) }\end{array}$ & $\begin{array}{l}\text { Shape of } \\
\text { cross-section }\end{array}$ & $\begin{array}{l}\text { Width of } \\
\text { cross-section }(\mathrm{m})\end{array}$ & $\begin{array}{l}\text { Side-slope } \\
(\mathrm{H}: \mathrm{V})\end{array}$ & $\begin{array}{l}\text { Routing } \\
\text { method }\end{array}$ \\
\hline 1 & $\mathrm{R}-1$ & 2,734 & 4.0 & \multirow{4}{*}{ Trapezoidal } & 50.0 & 1.9 & \multirow{4}{*}{$\begin{array}{l}\text { Kinematic } \\
\text { wave }\end{array}$} \\
\hline 2 & $\mathrm{R}-2$ & 3,216 & 1.6 & & 38.0 & 1.0 & \\
\hline 3 & $\mathrm{R}-3$ & 5,626 & 5.0 & & 50.0 & 1.3 & \\
\hline 4 & $\mathrm{R}-4$ & 5,536 & 4.9 & & 80.0 & 1.1 & \\
\hline
\end{tabular}




\subsubsection{Model Calibration}

All parameters used in the hydrological analyses at the very beginning were set according to the reference manual of HEC-HMS software, so as the specified conditions concerning the analyses in the watershed. Then the model calibration for reasonable values of key parameter $(\mathrm{CN})$ for each subbasin was performed using the historical streamflow data at Lianhuayan hydrological station, and the corresponding historical rainfall data at Liangshuijing rain gauge station during June 26-27, 1966 flood event. In fact, the available historical rainstorm-runoff data is badly lacking in this watershed. Fortunately, the rainstorm-streamflow data in 1966 flood event is available. The objective function provided by HEC-HMS computer software includes sum of absolute errors, sum of squared residuals, percent error in peak and peak-weighted root mean square error, which were used to find reasonable parameters that yield the minimum value of the objective function. In this study, the best one is the function of sum of absolute errors. Table 1 presents the reasonable calibrated $\mathrm{CN}$ value, while Fig. 4 demonstrates the comparison between the computed and field measured flood hydrograph at Lianhuayan hydrological station. As illustrated in Fig. 4, both computed temporal and numeric results of the peak discharge were well agreed with the measured data, which indicates the model was reliable for further analyses.

\subsection{Considerations on Critical Rainfall Analysis}

Generally speaking, given storm pattern or hyetograph, rain duration, warning discharge threshold and initial soil moisture content, critical rainfall can be investigated. There presents how to consider these factors in this study.

\subsubsection{Rainfall Duration}

Durations of critical rainfall, most part of leading time of early warning for flash flood are related to various factors, for instance, catchment area and shape, rainfall intensity, topography, vegetation, soil type, etc.. The rainstorm-runoff processes for small basins are largely depended on basin topography and water course characteristics, and the time of concentration of the basin has a significant impact on basin warning rainfall duration, which can be regarded as the longest warning rainfall duration for early warning. In addition, a series of shorter leading times should also

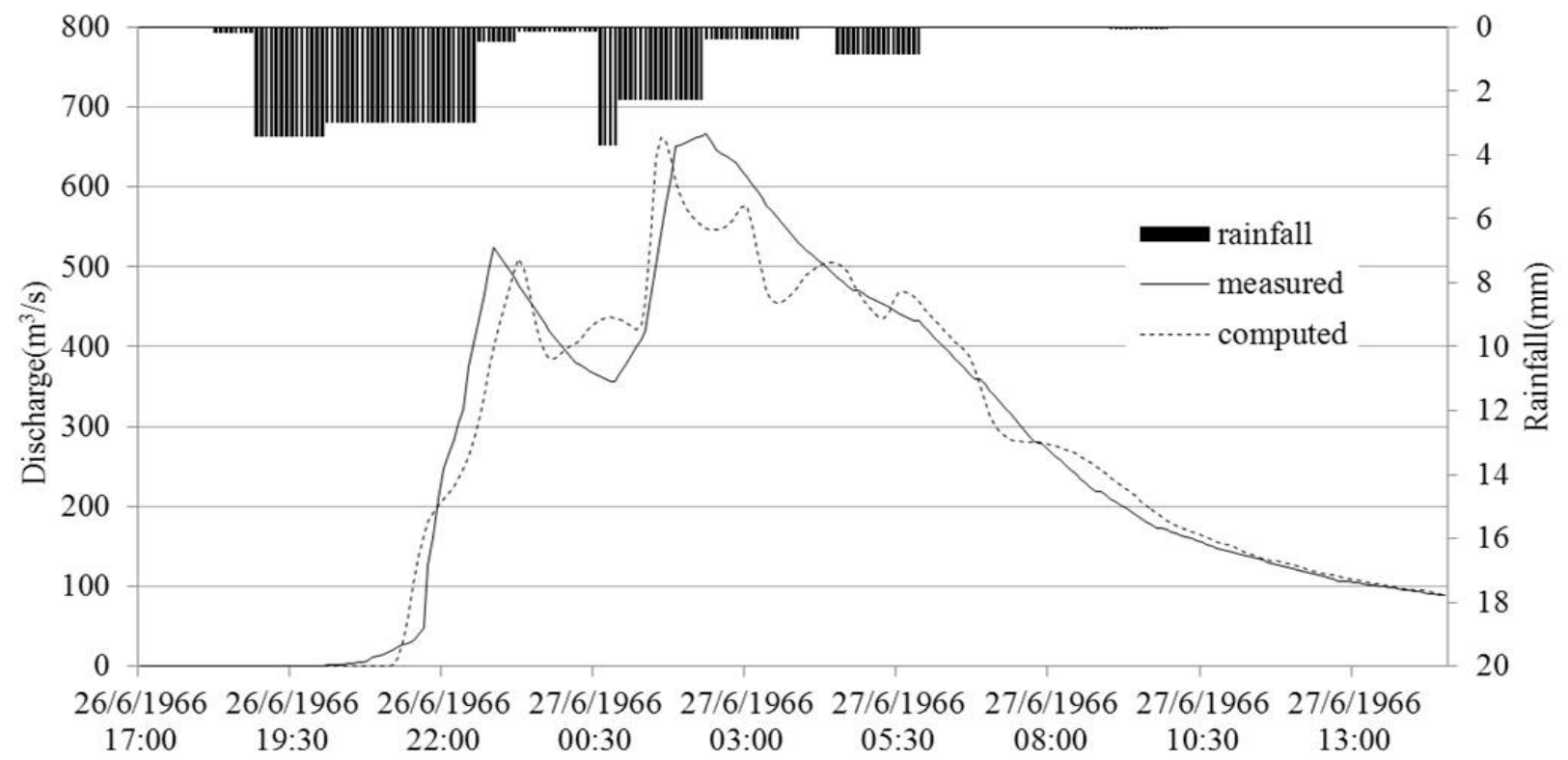

Fig. 4 Comparison between the computed and measured flood process at Lianhuayan hydrological station, on June 26-27, 1966. 
be considered based on factors such as rainstorm characteristics, basin area, basin slope, shape factors, surface conditions, etc..

Using rainfall intensity described in "Manual for Rainstorm-runoff Analysis in Hunan Province" and rational method, the time of concentration for the watershed is generally estimated to be over $5 \mathrm{~h}$ [19].

The rational method for estimating time of concentration is:

According to Chen, J. Q. [20], mean concentration velocity at basin level $\left(v_{\tau}\right)$ is used to reflect the characteristics of slope concentration and channel concentration:

$$
v_{\tau}=m J^{\alpha} Q_{m}^{\beta}
$$

That provide the time of concentration of basin as Eq. (2):

$$
\tau=0.278 \frac{L}{V_{\tau}}=0.278 \frac{L}{m J^{\alpha} Q_{m}^{\beta}}
$$

Where, $\tau$-time of concentration, hr; L-the longest distance from the river mouth to the divide of basin, $\mathrm{km}$; $\mathrm{J}$-the mean slope of $\mathrm{L}$; $m$-experimental parameter for concentration; $Q_{m}$-peak discharge, $\mathrm{m}^{3} / \mathrm{s}$; $\alpha, \beta$-experimental exponent parameter, $1 / 3$ and $1 / 4$ for triangular cross section in mountainous and hilly area.

Table 3 presents the results and values of parameters for time of concentration that is over $5 \mathrm{~h}$. Hence, the time of concentration of the watershed was determined as $6 \mathrm{~h}$ in this study. However, warning rainfall duration of $12 \mathrm{~h}$ was added for the sake of operation and safety, and the rainfall duration of $1 \mathrm{~h}, 3 \mathrm{~h}, 6 \mathrm{~h}$ and $12 \mathrm{~h}$ were chosen as warning rainfall duration for critical rainfall analysis.

\subsubsection{Warning Discharge Threshold}

The threshold discharges for early warning at 3 early warning stations (A, B and C) were determined based on the threshold river stage and the river cross section at each location. Manning's formula was used to convert threshold river stage to threshold discharge. The results are listed in Table 4.

\subsubsection{Initial Soil Moisture Content}

Soil moisture content has a significant impact on watershed runoff, consequently, will affect the critical rainfall estimation for each warning station. Due to serious shortage of data on soil moisture content, 3 scenarios, similar to antecedent soil moisture class were taken into consideration to simply and simulate soil moisture content in the entire watershed. They are: (1) dry antecedent soil moisture, simulating drought preceding condition (AMC I); (2) normal antecedent soil moisture, simulating normal preceding condition AMC II) and (3) wet antecedent soil moisture AMC III), simulating wet preceding condition. Watershed maximum storage capacity $\left(\mathrm{W}_{\mathrm{m}}\right)$ of $100 \mathrm{~mm}$ was obtained from "Manual for Rainstorm-runoff Analysis in Hunan Province". Based on the maximum storage capacity of the watershed, the watershed storage capacities are set as $50 \mathrm{~mm}$ for scenario $1,75 \mathrm{~mm}$ for scenario 2, and $90 \mathrm{~mm}$ for scenario 3. Consequently, the initial losses for 3 scenarios are $50 \mathrm{~mm}, 25 \mathrm{~mm}$ and $10 \mathrm{~mm}$, respectively.

Table 3 The results and values of parameters for time of concentration.

\begin{tabular}{lllllll}
\hline $\mathrm{L}(\mathrm{km})$ & $\mathrm{J}(\%)$ & $m$ & $Q_{m}\left(\mathrm{~m}^{3} / \mathrm{s}\right)$ & $\alpha$ & $\beta$ & $\tau(\mathrm{hr})$ \\
\hline 33.6 & 7 & 1.6 & 1,347 & $1 / 3$ & $1 / 4$ & 5.05 \\
\hline
\end{tabular}

Table 4 Summary of threshold discharge at each early warning station.

\begin{tabular}{lllllll}
\hline $\begin{array}{l}\text { Warning } \\
\text { station }\end{array}$ & $\begin{array}{l}\text { River slope } \\
(\%)\end{array}$ & $\begin{array}{l}\text { Manning's } \\
\text { coefficients } \\
(\mathrm{n})\end{array}$ & $\begin{array}{l}\text { Ave. velocity } \\
(\mathrm{m} / \mathrm{s})\end{array}$ & $\begin{array}{l}\text { Cross section } \\
\text { area } \\
\left(\mathrm{m}^{2}\right)\end{array}$ & $\begin{array}{l}\text { Threshold } \\
\text { discharge } \\
\left(\mathrm{m}^{3} / \mathrm{s}\right)\end{array}$ & Note \\
\hline A & 0.86 & 0.035 & 2.87 & 470 & 1,347 & Long pond \\
B & 2.5 & 0.035 & 2.90 & 81.4 & 670 & Matoupu town \\
C & 4.5 & 0.045 & 4.12 & 120 & 494 & Yangma border \\
\hline
\end{tabular}




\subsubsection{Storm Pattern}

As described in section 3.1 of this paper, the $24 \mathrm{~h}$ precipitation series was constructed by assuming an initial total rainfall depth and distributing the total rainfall depth to each time step based on the rainfall pattern. The rainfall depths of $1 \mathrm{~h}, 3 \mathrm{~h}, 6 \mathrm{~h}$ and $12 \mathrm{~h}$ were converted from $24 \mathrm{~h}$ rainfall. That is to say the critical rainfall analysis requires the distribution of $1 \mathrm{~h}$ storm, $3 \mathrm{~h}$ storm, $6 \mathrm{~h}$ storm and $12 \mathrm{~h}$ storm as initial input to match the warning discharge thresholds for each warning station.

The following three storm patterns for various durations were taken into consideration in this study for the purpose of finding out the responses of critical rainfall of flash flood to storm pattern: (1) basic storm hyetograph (Hyeto 1); (2) decreasing rate hyetograph (Hyeto 2) and (3) increasing rate hyetograph (Hyeto 3).

(1) Basic storm hyetograph (Hyeto 1): a frequency-based hypothetical storm temporal distribution and showing scenario of heavy rain in the middle and light rain in both the beginning and rear of a rainstorm event. This storm pattern was statistically obtained base on many year's rainstorm data in Hunan province. Table 5 presents the methods to compute this storm hyetograph of various typical rainfall duration according to "Manual for Rainstorm-runoff Analysis in Hunan Province".

In "Manual for Rainstorm-runoff Analysis in Hunan Province", the mean $24 \mathrm{~h}$ precipitation $\left(H_{24}\right)$ can be found out in its isopluvial maps, and converted into rainfall depth of various duration:

$$
\left\{\begin{array}{l}
H_{t}=H_{24} \cdot 24^{n_{3}-1} \cdot 6^{n_{2}-n_{3}} \cdot t^{1-n_{2}} \quad 1 h \leq t \leq 6 h \\
H_{t}=H_{24} \cdot 24^{n_{3}-1} \cdot t^{1-n_{3}} \quad 6 h<t \leq 24 h
\end{array}\right.
$$

Where, $H_{t}$-rainfall depth of $t$-hour duration, mm; $n_{2}, n_{3}$-attenuation coefficients for rainstorm duration of 1-6 $\mathrm{h}$ and 6-24 h, respectively.

(2) Decreasing rate storm hyetograph (Hyeto 2): this storm pattern gets the rainfall series of basic storm hyetograph in descending order of each time interval of duration, and describes scenario of heavy rain in the very beginning and light rain in the rear of a rainstorm event.

(3) Increasing rate storm hyetograph (Hyeto 3): this storm pattern presents the rain series of basic storm hyetograph in increasing order of each time interval of

Table 5 Basic rainfall pattern used in critical rainfall analysis.

\begin{tabular}{|c|c|c|c|c|c|c|c|c|c|c|c|c|}
\hline$\Delta \mathrm{t}=15 \mathrm{~min}$ & \multicolumn{4}{|c|}{$t_{d}=1 \mathrm{~h}$} & \multirow{3}{*}{ / } & & & & & & & \\
\hline Duration & 1 & 2 & 3 & 4 & & & & & & & & \\
\hline Rainfall (\%) & 16 & 30 & 32 & 22 & & & & & & & & \\
\hline$\Delta \mathrm{t}=30 \min$ & $t_{d}=3$ & & & & & & & & & & & \\
\hline Duration & 1 & 2 & 3 & 4 & 5 & 6 & & & & & & \\
\hline Equivalent to H1 (\%) & & & 38 & 62 & & & & & & & & \\
\hline Equivalent to (H3-H1) (\%) & 21.7 & 35.5 & & & 26.6 & 16.2 & & & & & & \\
\hline$\Delta \mathrm{t}=30 \mathrm{~min}$ & $t_{d}=6$ & & & & & & & & & & & \\
\hline Duration & 1 & 2 & 3 & 4 & 5 & 6 & 7 & 8 & 9 & 10 & 11 & 12 \\
\hline Equivalent to H1 (\%) & & & & & & & 38 & 62 & & & & \\
\hline Equivalent to (H3-H1) (\%) & & & & & 21.7 & 35.5 & & & 26.6 & 16.2 & & \\
\hline Equivalent to (H6-H3) (\%) & 16 & 17 & 18 & 20 & & & & & & & 15 & 14 \\
\hline$\Delta \mathrm{t}=60 \mathrm{~min}$ & $t_{d}=1$ & & & & & & & & & & & \\
\hline Duration & 1 & 2 & 3 & 4 & 5 & 6 & 7 & 8 & 9 & 10 & 11 & 12 \\
\hline Equivalent to $\mathrm{H} 1(\%)$ & & & & & 100 & & & & & & & \\
\hline Equivalent to (H3-H1) (\%) & & & & 49.2 & & 50.8 & & & & & & \\
\hline Equivalent to (H6-H3) (\%) & & & & & & & 39.8 & 31.1 & 29.1 & & & \\
\hline Equivalent to (H12-H6) (\%) & 11.3 & 19.1 & 19.1 & & & & & & & 29.6 & 13.9 & 7 \\
\hline
\end{tabular}

\footnotetext{
$* \mathrm{t}_{\mathrm{d}}$ is rainfall duration, $\Delta \mathrm{t}$ is time interval of duration, $\mathrm{H} 1 \mathrm{is} 1 \mathrm{~h}$ rainfall depth.
} 
duration, and provides scenario of light rain in the front and heavy rain in the very rear of a rainstorm event.

\section{Results and Analysis}

Using hydrological model, given storm pattern, rainfall duration and initial soil moisture content based on AMC index, the responses of critical rainfall for flash flood to storm pattern at 3 warning stations (A, B and $C$ ) were investigated. Independent simulations were conducted for all the combination of duration (1 h, $3 \mathrm{~h}, 6 \mathrm{~h}$ and $12 \mathrm{~h}$ ), storm patterns (Hyeto 1, Hyeto 2 and Hyeto 3) and AMC classes (AMC I, AMC II and AMC III). The critical rainfalls were iterative identified by trial and error method until the discharge threshold at each warning station reaches acceptable margin of error. Fig. 5 presents the results. The following groups are made for the purpose of clear narration. Group A, including A(AMC) and A(Hyeto), represents three typical antecedent soil moisture conditions and storm patterns at warning station $\mathrm{A}$. Similarly, Group B (including B(AMC) and B(Hyeto)) and Group $\mathrm{C}$ (including $\mathrm{C}(\mathrm{AMC})$ and $\mathrm{C}($ Hyeto)) stands for antecedent soil moisture conditions and storm patterns at warning station $B$ and warning station $C$, respectively. $\mathrm{A}(\mathrm{AMC})$ consists of $\mathrm{A}(\mathrm{AMC} \mathrm{I}), \mathrm{A}(\mathrm{AMC}$ II) and A(AMC III), while $\mathrm{A}$ (Hyeto) consists of $\mathrm{A}$ (Hyeto 1), $\mathrm{A}$ (Hyeto 2) and $\mathrm{A}$ (Hyeto 3 ). And this is same to $\mathrm{B}(\mathrm{AMC}), \mathrm{B}$ (Hyeto), $\mathrm{C}(\mathrm{AMC})$ and $\mathrm{C}$ (Hyeto). The analysis on Fig. 5 provides the understandings:

(1) The critical rainfall depths are descending ordered as Hyeto 2, Hyeto 1 and Hyeto 3 at each warning station for same rainfall duration and soil moisture content. In other words, the first response of critical rainfall to storm pattern is, for same rainfall duration and soil moisture content, a rainstorm with rain peak in the front of hyetograph needs much more accumulative rain amount than that with rain peak in the end of hyetograph. Taking A(AMC I) and duration $6 \mathrm{~h}$ as an example, the amount of critical rainfall is only $120 \mathrm{~mm}$ for Hyeto 3, $128 \mathrm{~mm}$ for Hyeto1, but $176 \mathrm{~mm}$ for Hyeto 2, and the analysis on other cases (A(AMC II), A(AMC III), B(AMC I), B(AMC II), B(AMC III) and C(AMC I), C(AMC II), C(AMC III)) presents different values but the same trend.

(2) The second response is, critical rainfall depths increase with rainfall duration at each warning station in the condition of sameinitial antecedent soil moisture. For same rainfall duration, the corresponding increments of critical rainfall amount are also descending ordered as Hyeto 2, Hyeto 1 and Hyeto 3. This indicates that storm pattern also plays important role in the estimation of critical rainfall while soil moisture content works to some degree in this procedure. Taking A(AMC III) as example, the amounts of critical rainfall increase from $77 \mathrm{~mm}$ at $1 \mathrm{~h}$, to $102 \mathrm{~mm}$ at $3 \mathrm{~h}$, to $116 \mathrm{~mm}$ at $6 \mathrm{~h}$, to $153 \mathrm{~mm}$ at $12 \mathrm{~h}$ for Hyeto 1 . And increase from $78 \mathrm{~mm}$ at $1 \mathrm{~h}$, to 118 $\mathrm{mm}$ at $3 \mathrm{~h}$, to $159 \mathrm{~mm}$ at $6 \mathrm{~h}$, to $201 \mathrm{~mm}$ at $12 \mathrm{~h}$ for Hyeto 2. But only increase from $77 \mathrm{~mm}$ at $1 \mathrm{~h}$, to 102 $\mathrm{mm}$ at $3 \mathrm{~h}$ to $112 \mathrm{~mm}$ at $6 \mathrm{~h}$, to $126 \mathrm{~mm}$ at $12 \mathrm{~h}$ for Hyeto 3, Table 6 presents the details. The analysis on other cases (A(AMC I), A(AMC II), B(AMC I), B(AMC II), B(AMC III) and C(AMC I), C(AMC II), $\mathrm{C}(\mathrm{AMC}$ III)) also indicates different values but the same tendency.

(3) The third response is that the accumulative rainfall curves at similar antecedent soil moisture

Table 6 Different increment of critical rainfall for storm pattern A(AMC III).

\begin{tabular}{lccclll}
\hline $\begin{array}{l}\text { Duration } \\
(\mathrm{h})\end{array}$ & \multicolumn{3}{c}{ Critical rainfall $(\mathrm{mm})$} & \multicolumn{2}{c}{ Increment $(\mathrm{mm})$} \\
\cline { 2 - 7 } & Hyeto 1 & Hyeto 2 & Hyeto 3 & Hyeto 1 & Hyeto 2 & Hyeto 3 \\
\hline 1 & 77 & 78 & 77 & $/$ & $/$ & $/$ \\
3 & 102 & 118 & 102 & 25 & 40 & 25 \\
6 & 116 & 159 & 112 & 14 & 41 & 10 \\
12 & 153 & 201 & 126 & 37 & 42 & 14 \\
\hline
\end{tabular}



Pattern in South Branch of Censhui Watershed
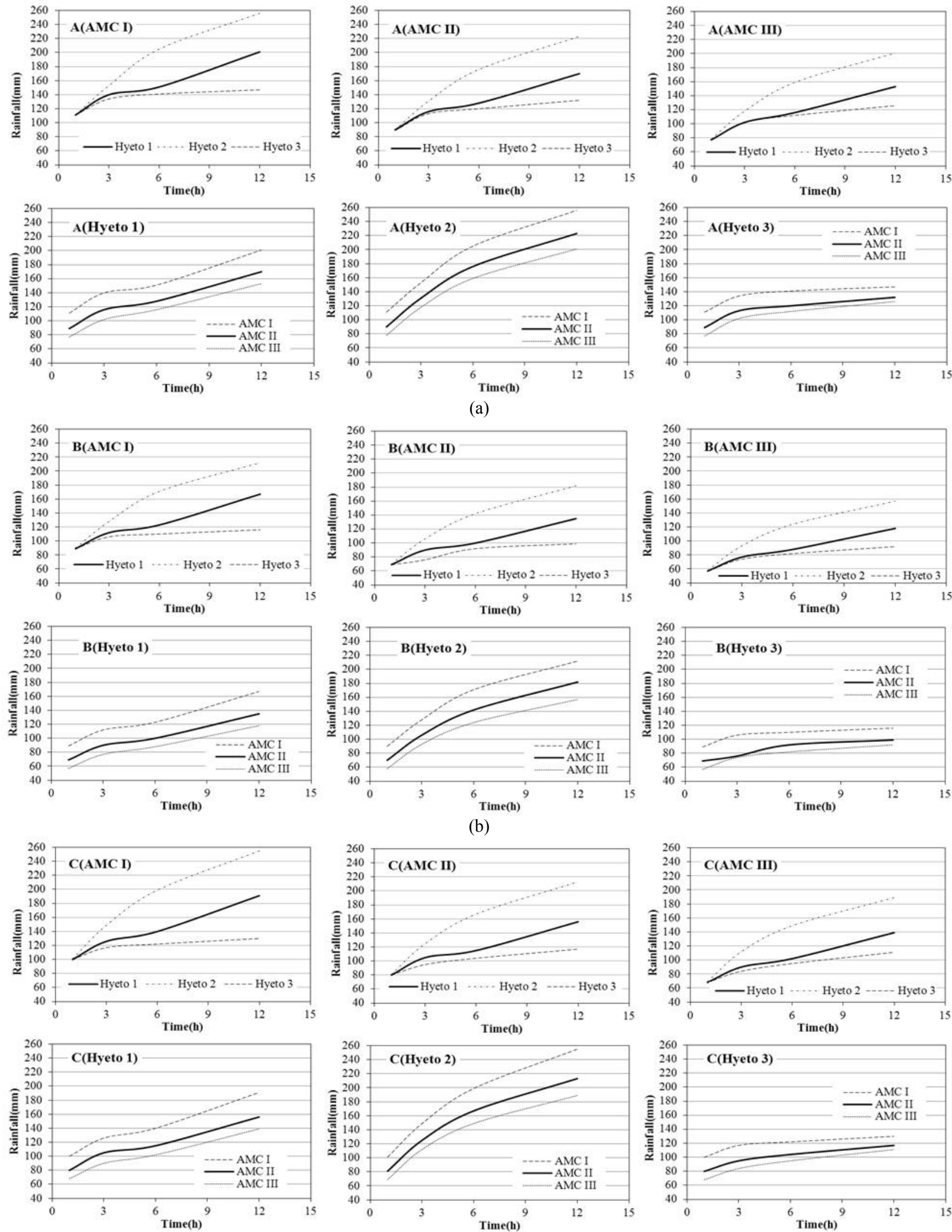

(c)

Fig. 5 Critical rainfalls for given storm patterns, rainfall duration, warning discharge threshold, and initial soil moisture content at three warning stations ((a) Station A, (b) Station B and (c) Station C). 
condition are quite different for various storm patterns. Specifically, Hyeto 2 has a highly steep curve while Hyeto 3 has a relative mild one, and that of Hyeto 1 is between those of Hyeto 2 and Hyeto 3 (A(AMC), $\mathrm{B}(\mathrm{AMC})$ and $\mathrm{C}(\mathrm{AMC})$ for each storm pattern). Meanwhile, the accumulative rainfall curves of same storm pattern are not also the same for different soil moisture condition (A(Hyeto), B(Hyeto) and C(Hyeto) for each antecedent soil moisture condition). For each warning station, the curves of "AMC I" are highly steep, relatively mild of "AMC III". This phenomenon results from the surface storage and infiltration in the watershed. In storm pattern of Hyeto 2, heavy rain occurs at the very begging of a storm event, some, even most of the heavy rain is to feed surface storage in the watershed. The latter rainfall intensity is not usually strong enough to trigger flash flood until accumulative rainfall amount reaches up to a considerable degree. In storm pattern of Hyeto 3, some of the first half rainfall has met the requirements of surface storage and infiltration in the catchment, and the second half is heavy rain that is strong enough to trigger flash flood. Obviously, the rainfall-runoff process of Hyeto 1 is between Hyeto 2 and Hyeto 3 in that heavy rainfall occurs in the mid of a rainstorm event.

(4) Fig. 5 also indicates that, for same critical rainfall depth, the rainfall durations of corresponding storm pattern are increasing ordered as Hyeto 2, Hyeto 1 and Hyeto 3. As A(AMC I), taking critical rainfall as 140 $\mathrm{mm}$, the leading times are $2.5 \mathrm{~h}$ for Hyeto $2,3 \mathrm{~h}$ for Hyeto 1, and $5 \mathrm{~h}$ for Hyeto 3, respectively. The analysis on other cases (A(AMC II), A(AMC III), B(AMC I), B(AMC II), B(AMC III) and C(AMC I), C(AMC II), C(AMC III)) also presents different values but same trend, which means Hyeto 3 will produce more leading time for flash flood early warning than Heyto 1 and Hyeto 2 . And the leading time of Hyeto 2 is the shortest one. This is an extension or application of the response of critical rainfall to storm pattern which indicates that rainstorm pattern should be considered for the purpose of obtaining leading time as much as possible.
The above analysis indicates that critical rainfall for flash flood early warning is highly complicated due to various storm pattern and soil moisture conditions, and the responses of critical rainfall to storm pattern absolutely are not simple even antecedent soil moisture conditions are similar. To estimate critical rainfall, one important way is to find out the upper and lower enveloping curves in which various factors were taken into consideration. Those factors include at least storm pattern or hyetograph, rain duration, warning discharge threshold and initial soil moisture content. Fig. 6 presents two types of upper and lower enveloping curves of critical rainfall for each warning station. The first one considering both storm pattern and antecedent soil moisture conditions is shown by Fig. 6a and the second one only considering antecedent soil moisture condition is shown by Fig. 6b. The two enveloping curves are quite different, strongly indicating the significant responses of critical rainfall to storm pattern.

\section{Remarks}

This paper started with summarizing critical rainfall analysis methods, then the research concept and approach critical rainfall analysis was introduced to investigate the responses of critical rainfall to storm pattern. Three storm patterns were taken into consideration in this study: (1) Hyeto 1, a frequency-based hypothetical storm temporal distribution, refers to scenario of heavy rain occurring in the middle and light rain in both the beginning and rear of a rainstorm event; (2) Hyeto 2, decreasing rate hyetograph, describes scenario of heavy rain in the very beginning and light rain in the rear of a rainstorm event and (3) Hyeto 3, increasing rate hyetograph, provides scenario of light rain in the front and heavy rain in the very rear of a rainstorm event. Taking the south branch of Censhui watershed in Hunan province as an example, the responses were investigated by analyzing critical rainfall to storm patterns of Hyeto 1, Hyeto 2 and Hyeto 3 at 3 early warning stations. The outcomes of this study are: 

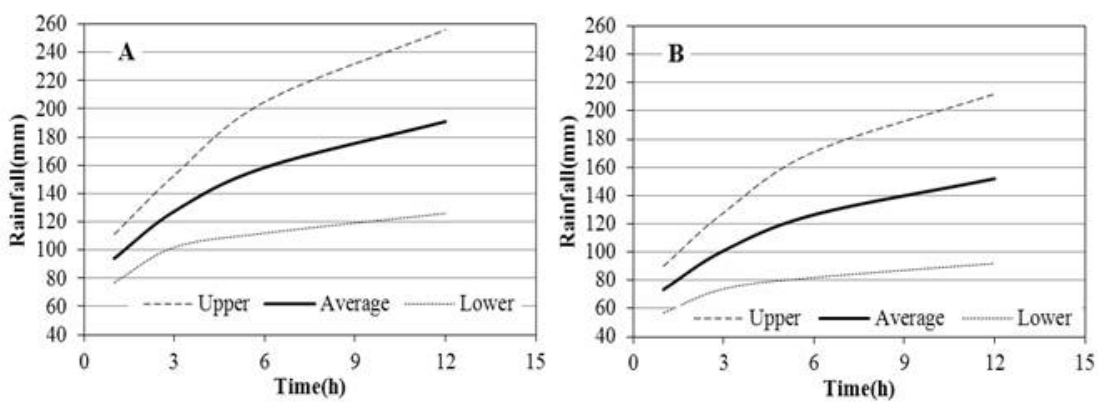

(a)
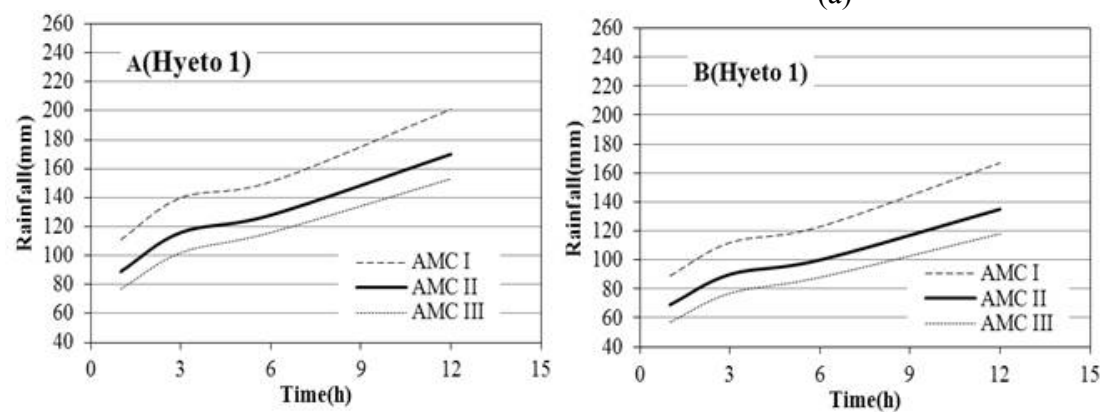

(b)
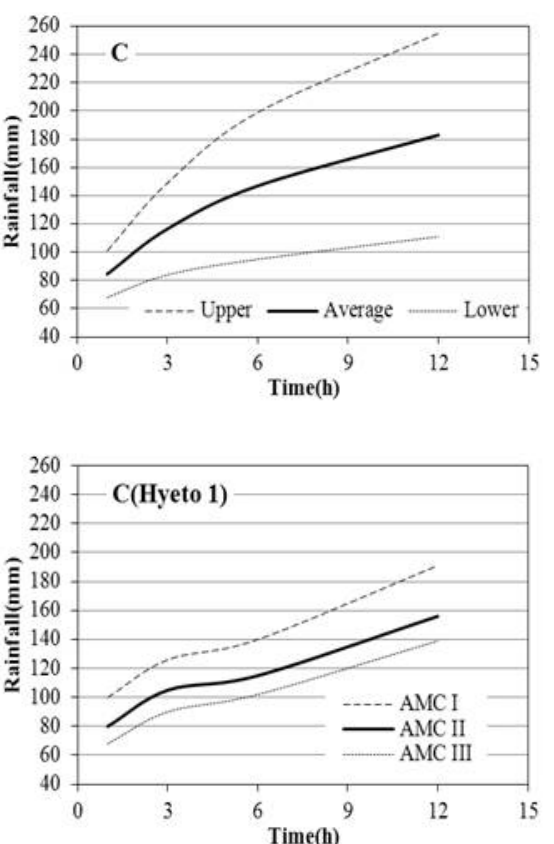

Fig. 6 Upper and lower enveloping curves of critical rainfall at three warning stations ((a) enveloping curves of critical rainfall considering storm pattern and antecedent soil moisture conditions and (b) enveloping curves of critical rainfall only considering antecedent soil moisture conditions).

(1) For rainstorm-induced flash flood, one rainstorm event with rain peak in the front of hyetograph needs much more accumulative rain amount than that with rain peak in the end of hyetograph in the circumstance of same rainfall duration and soil moisture content. The results presents that critical rainfall depths are descending ordered as Hyeto 2, Hyeto 1 and Hyeto 3 at each warning station for same rainfall duration and soil moisture content.

(2) Similar to antecedent soil moisture conditions, storm pattern has significant impact on the estimation of critical rainfall. The result provides that for each antecedent soil moisture conditions of drought, normal and wet, critical rainfall depths increase with rainfall duration at each warning station and the corresponding increments of critical rainfall for same rainfall duration is also descending ordered as Hyeto 2, Hyeto 1 and Hyeto 3.

(3) The accumulative rainfall curves at similar antecedent soil moisture condition are quite different for various storm patterns; in this regard, Hyeto 2 has a highly steep curve while Hyeto 3 has a relative mild one, and that of Hyeto 1 is between those of Hyeto 2 and Hyeto 3.

(4) The response of critical rainfall to storm pattern indicates the reference for leading time of early warning. The results in this study demonstrate that, for same critical rainfall depth, the rainfall durations of corresponding storm pattern are increasing ordered as Hyeto 2, Hyeto 1 and Hyeto 3, which indicates that rainstorm pattern should be considered for the purpose of obtaining leading time as much as possible.

(5) Critical rainfall depth estimation is performed by inverse hydrologic process which is not a deterministic process, but a diverging process. The analysis indicates that critical rainfall for flash flood early warning is highly complicated due to various storm pattern and soil moisture conditions, and the response of critical rainfall to storm pattern is not simple even at same soil moisture condition. The upper and lower enveloping curves of critical rainfall considering both storm pattern and antecedent soil moisture conditions are much more than that only considering antecedent soil moisture condition. 


\section{Acknowledgements}

Thanks for finical support of project "China National Flash Flood Hazard Prevention and Control", and project "Theory and Method on Basin Level Flood and Drought Hazard Risk Management" (Jian No.0101092013).

\section{References}

[1] Sweeney, T. L. 1992. Modernized Areal Flash Flood Guidance. U.S.: National Weather Service.

[2] Carpenter, T. M. 1999. "National Threshold Runoff Estimation Utilizing GIS in Support of Operational Flash Flood Warning Systems." Journal of Hydrology 224 (1-2): 21-44.

[3] Flood Site. 2008. Realtime Guidance for Flash Flood Risk Management. Project report.

[4] Georgakakos, K. P. 1992. "Advances in Forecasting Flash Floods." In Proceedings of the CCNAA-AIT Joint Seminar on Prediction and Damage Mitigation of Meteorologically Induced Natural Disasters, 280-293.

[5] Sperfslage, J. A., Georgakakos, K. P., Carpenter, T. M., Shamir, E., Graham, N. E., and Alfaro, R. et al. 2004. Central America Flash Flood Guidance (CAFFG) User's Guide. HRC Limited Distribution report.

[6] Sweeney, T. L. 1992. Modernized Areal Flash Flood Guidance. NOAA Technical report.

[7] Konstantine Georgakakos, P. 2006. "Analytical Results for Operational Flash Flood Guidance." Journal of Hydrology 317: 81-103.

[8] Chen, G. Y., and Yuan Y. M. 2005. "Research on Critical Precipitation Amount Computation Method of Mountain Torrential Flood Disaster." Yangtze River 36 (12): 40-43.

[9] Ye, Y., Wang, Z. Y., and Fan, B. Q. 2008. "Flash Flood Critical Rainfall Estimation for Small Watershed in Jiangxi Province.” Journal of Hydrology 28 (1): 56-58.

[10] Jiang, J. H., and Shao, L. P. 2010. "Standard of Mountain
Flood Warning Based on the Precipitation Observation Data." Journal of Hydraulics 41 (4): 458-463.

[11] Wang, X., Cao, Z. X., and Tan, G. M. 2009. "Shallow Water Hydrodynamic Modelling of Rainfall Induced Flash Flooding." Engineering Journal of Wuhan University 42 (4): 413-416.

[12] Jan, C. D., Lee, M. H., and Wang, J. S. 2004. "A Rainfall-Based Debris-Flow Warning Model and Its Application in Taiwan." In International Conference on Slope Disaster Mitigation Strategy, 111-119.

[13] Jan, C. D., Lee, M. X., and Guo, F. H. 2006. "Rainfall Warning Mode for Spatial and Temporal Characteristics of Debris Flow." Geotechnical Technology 110 (3): 55-64.

[14] Eve Gruntfest. 2001. "Beyond Flood Detection: Alternative Applications of Real-Time Data." NATO Science Series 77: 167-179.

[15] Norbiato, D. 2008. "Flash Flood Warning Based on Rainfall Thresholds and Soil Moisture Conditions: An Assessment for Gauged and Ungauged Basins.” Journal of Hydrology 362 (3-4): 274-290.

[16] Montesarchio, V. 2009. "Rainfall Thresholds and Flood Warning: An Operative Case Study." Natural Hazards and Earth System Science 9 (1): 135-144.

[17] Montesarchio, V. 2011. "Rainfall Threshold Definition Using an Entropy Decision Approach and Radar Data." Natural Hazards and Earth System Science (7): 2061-2074.

[18] Brath, A. 2001. "Estimating the Index Flood Using Indirect Methods." Hydrological Sciences Journal 46 (3): 399-418.

[19] Chen, J. Q., and Zhang, G. S. 1984. Rainstorm-Runoff Computation for Small Watershed. Beijing: Water Resources and Hydropower Press.

[20] Hunan Provincial Department of Water Resources and Hydropower. 1984. Manual for Rainstorm-Runoff Analysis in Hunan Province. Changsha: Water Resources and Hydropower Press. 